\title{
Meeting the cost demand: A parametric approach to facility assessment and appraisal
}

Received (in revised form): 21st February, 2007

\section{Cornelia E. Demers}

is Associate Professor in the Department of Civil, Construction and Environmental Engineering at the Wentworth Institute of Technology, Boston, USA. She joined the faculty at WIT after completing a Visiting Professorship at the University of Arizona. She was awarded the prestigious NSF Visiting Professorship for Women at the Georgia Institute of Technology. She holds numerous awards for her teaching efforts. Her professional experience includes industry as well as the Volpe National Transportation Systems Center. She earned a PhD in Civil Engineering at WPI and is a registered professional engineer.

\begin{abstract}
Rita Oberle
held tenured faculty dual appointments Engineering and Architecture. She is the former Director, Facilities for the Centers of Disease Control and Prevention. She joined the faculty at Georgia Tech after completing a distinguished 25-year career in various engineering and research positions for the Department of Defense. She earned a PhD in Civil Engineering from the University of Florida. She was a fellow in the Senior Executive Fellows Program, Kennedy School of Government at Harvard University, and the Construction Executive Program at Stanford University. She is a registered Professional Engineer and a nationally Certified Cost Analyst.
\end{abstract}

Correspondence: Cornelia E. Demers, Department of Civil, Construction \& Environment, Wentworth Institute of Technology, Boston, MA, USA; Tel: +1 617989 4118; Fax: +1 617989 4172; E-mail: demersc1@wit.edu

\begin{abstract}
The US Federal Agencies, including the Federal Highway Administration, recommend and in some case require rehabilitation alternatives before replacing a facility or bridge structure to effectively use available federal funds. The goal of facility management is to assess the structures most critically in need of repair/ strengthening, decide the appropriate retrofit, and control cost. A project-level analysis is needed to assess costs associated with alternative repair procedures for specific facility and infrastructure treatments. The objective of this paper is to report the design and conceptual basis of a project-level cost-benefit model for infrastructure and facility management. This modelling approach addresses the process of constructing the repair, providing resulting costs, that build on the patented Parametric Automated Cost Engineering System and contributes new and fundamental interdisciplinary systems-based knowledge applicable to facilities and bridge infrastructure systems. This model design provides: economically smart repair/strengthening options; a fundamentally new process documenting the decision processes; an audit trail on repair alternatives; and the basis for documenting lessons learned. The context of this paper uses the most recent applications to bridge repair, but builds on over 15 years experiences of usage and application of this modelling approach to vertical (buildings) and horizontal (infrastructure) facility management. Journal of Building Appraisal (2007) 3, 104-114. doi:10.1057/palgrave.jba.2950066
\end{abstract}

\section{Keywords:}

parametric cost engineering, cost-benefit, facilities, bridges, model, Pontis 


\section{INTRODUCTION}

The Parametric Automated Cost Engineering System (PACES) was originally developed for military construction projects and was intended to support the certification and estimating needs of the military engineering community. The US Congress approved PACES for military construction Budget Estimate Submittals. The PACES methodology has been fielded and tested on a large variety of construction and environmental remediation projects (Gregory, 1992; Gallaher and Gregory, 1993). It has since been modified and licensed for commercial use and is currently used by hundreds of designers and constructors for new building construction and renovation projects.

Similar to the building construction industry, for bridge strengthening and deterioration repairs, the Federal Highway Administration (FHWA), as well as other Federal agencies, recommends that the States, in developing construction projects, consider the rehabilitation alternative before deciding to replace a structure (FHWA, 2002). This suggestion encourages the efficient use of available funds for facility improvement. In many cases, rehabilitation costs far less than replacement. By accomplishing rehabilitation early before deterioration reaches an advanced stage, a more costly replacement can be avoided and the repaired facility can provide reliable service for an extended period of time. The method by which a facility is evaluated for structural deficiency is usually a visual inspection. This process is labour-intensive and often subjective. As an improvement in US highway management, Pontis (Cambridge Systematics, Cambridge, MA) was developed as a means to record the condition of a bridge over time. This database of bridge condition is essential in assessing which structures are most critically deficient. Pontis provides a network-level analysis that does not include a project-level evaluation to assess costs associated with alternative repair procedures for a specific bridge treatment. A project-level analysis is highly needed in both bridge and facility management, to assist in the immense task of selecting economically smart repair/strengthen options available for traditional and innovative treatments of specific projects. The objective of this paper is to report research conducted by the authors in the design and conceptual basis of a project-level cost-benefit model for traditional and innovative bridge treatments that also apply to facilities.

\section{BACKGROUND AND RELATIONSHIP TO CURRENT STATE-OF-KNOWLEDGE}

Detailed literature searches (Gregory, 1992) through the Defense Technical Information Center (Poulis, 1995) and numerous patent searches through United States Air Force (USAF) applications to the United States Patent and Trademark Office (AFLSA/JACPD, 1993) showed numerous sources (Waid, 1978; USA, 1988; Yokoyama, 1988; Mendel, 1989; Ohara, 1990) discussing parametric cost estimating using techniques to statistically analyse historical data. None of the parametric estimating techniques, however, discussed the ability to forecast never-built-before engineering systems or the ability to project engineering solutions from emerging and dual use technologies. In 1995, Pontis was updated to Pontis BMS to include probabilistic models (based on the Markovian process) and a more detailed bridge database for assessing repair/rehabilitation needs. An extensive project (Bell, 1999), focusing on a cost system for bridges, was initiated to develop cost estimating relationships by analysing and conducting regression analyses on historical data. This project was shelved because the collected data were either largely lumped sum, historical data that did not have sufficient or specific bridge system and subsystem data or bid data that did not reflect actual cost. Sufficient detail was not kept to distinguish important cost drivers such as material, labour, and equipment changes, or traffic 
management impacts. These developments, however, included only historical data. Although these bridge cost analyses are valuable, they do not specifically address engineering decisions for dual use materials technologies for infrastructure rehabilitation. None of the reviewed literature claimed to predict construction estimates at the pre-design stage with sufficient accuracy for project definition decisions, engineering solutions, evaluations, value engineering analyses, or infrastructure renewal assessments. The expert systems literature (Rounds, 1986; AFCC, 1988; Arditi, 1991) discussed the applications of decision shells. The only relationship to cost estimating was the ability of some expert system shells to accept or transfer data to spreadsheets (or other specialised programs) for elementary mathematical calculations (Gregory, 1992). This project-level cost-benefit model for bridges and facility management does not recommend the application of currently popular off-the-shelf knowledge-based 'shell' expert systems. Instead, this model provides a totally new assessment technology that integrates heuristics, algorithms, and engineering data. To achieve this, the patented technology from the commercially licensed Parametric Cost Engineering System (PACES) provided a proven foundation from which this new cost-benefit technology for bridges is under development (AFLSA/ JACPD, 1993, PACES, 1997).

\section{PACES BACKGROUND AND VALIDITY}

PACES, as a patented and commercially proven foundation, was selected as the baseline cost engineering platform for this research. Full descriptions of this expert systems modelling are outside the scope of this paper but can be obtained from the Air Force (AFCESA, 1995) or the US Patent and Trademark Office (AFLSA/JACPD, 1993; Burns, 1993). PACES is not a 'black box', but uses well-documented cost engineering technology patented by the US Air Force (AFLSA/JACPD, 1993; AFCESA, 1995). PACES cost models use knowledge bases to create generic engineering solutions for construction projects, technologies, and processes. The generic engineering solutions were derived from engineering science and principles, and where available, historical project information, government laboratories, construction management agencies, vendors, contractors, and previous engineering analysis. PACES is unique in that a new technology can be described in engineering terms, no historical data are required. PACES, through expert system processes and algorithms, creates a detailed quantity-take-off estimate of material, labour, and equipment quantities priced against current cost data (not historical parametric factor analysis). These current cost data are updated at least annually by the military services.

PACES contains over 100 different cost models including 78 building models, 36 site work and utility models, a runway/taxiway model, and renovation models for all facility types. The building models represent 11 model groups including: Administrative/Office, Communications and Electronics, Dining, Dormitories, Hangars, Maintenance, Medical, Storage, Child Care, Housing, Lodging. Building parameters include physical properties that describe project definition characteristics such as size, building type, foundation type, exterior closure materials, roof type and material, number of floors, functional space requirements, and utility system requirements. Building models are comprised of Functional Space Areas (FSAs), which are pre-defined types of space. Examples of FSAs are: Closed Office, Open Office, Bathroom, Kitchen, Mechanical Room, etc. PACES contains over 250 different default FSAs. FSAs are comprised of cost data called 'Assemblies'. Assemblies are made up from a comprehensive cost database with over 
Table I: Parametric cost engineering test

\begin{tabular}{lccc}
\hline & Actual cost (\$000) & A/E 35\% (\% DIFF) & Parametric (\% DIFF) \\
\hline Education Center & 2145.0 & 1.8 & 0.2 \\
Aeromedical Trng & 1932.5 & -26.5 & -1.7 \\
Space Center & 90900.0 & 61.5 & 0.7 \\
Squadron Ops & 1218.0 & 14.9 & 10.8 \\
Acft Maint Shop & 2190.0 & -15.1 & 0.5 \\
Base Operations & 1082.0 & -17.7 & -15 \\
Gymnasium & 3055.0 & -11 & -14.9 \\
Maint Dock & 6378.4 & -11.7 & -2.8 \\
Aeromedical & 2091.1 & -11.8 & 2.8 \\
Project average & $\mathbf{1 2 3 3 2 . 4}$ & $\mathbf{1 9 . 2}$ & $\mathbf{5 . 5}$ \\
\hline
\end{tabular}

25,000 line items that are updated annually and can be modified to used defined assemblies and line items, for emerging technologies. Several accuracy tests (Gregory, 1992; Gallaher and Gregory, 1993) have been conducted comparing the parametric modelling system to a quantity survey estimating approach at the 35 per cent design stage. The parametric modelling system provided the more effective cost as shown in Table 1.

PACES also contains new construction for bridges as included under the Site Improvement Models. PACES uses quantities from standard models in developing its quantity-take-off estimate. As an example of a standard bridge type used to design the knowledge-based system algorithms in PACES, a Precast Beam Section is shown in Figure 1. The user can select among five standard bridge models for new construction. All quantities (material, labour, and equipment) for construction are based on the standard dimensions of the bridge type. The user is only required to input the length of the bridge. Additional data such as the height of the bridge and the number of spans are defaulted from standard designs, but may be changed and recorded by the user.

As further validation, The US Congress approved PACES for military construction Budget Estimate Submittals (BES).

- Resolution 395, 21st December, 1987, which states: 'The Air Force has developed a parametric cost modelling system that has the potential for providing cost estimates as an alternative to developing cost estimates based on 35 percent design status'. Congress required detailed reporting and accuracy tests before giving this resolution (Gregory, 1992).

- Congress Report 101-331, 7th November, 1989 which indicated that: 'In light of the maturing capability of parametric facility planning, the conferees have no objection to the use of parametric facilities planning for the basis of budget requests for military construction projects'.

- A comparative analysis of this patented parametric cost engineering and traditional cost estimating concluded, 'the budget estimates based on parametric cost engineering (sic) were judged more accurate'. The study concluded the parametric cost engineering method in estimating construction costs during the planning, programming, and budget phases of the facility acquisition (OASD, 1993).

Since its release in 1990, approximately 1,400 government employees, contractors, and commercial estimators have used the system to estimate facilitates ranging in cost from a few thousand to hundreds of millions of dollars (AFCESA, 1995). 


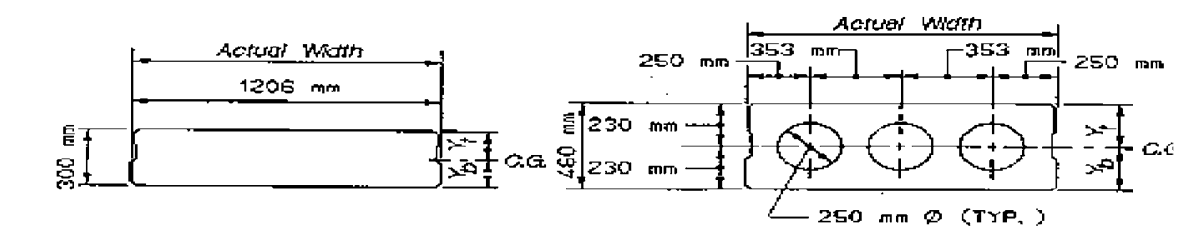

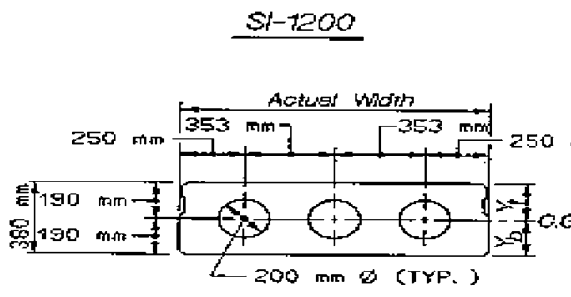

SH-1200

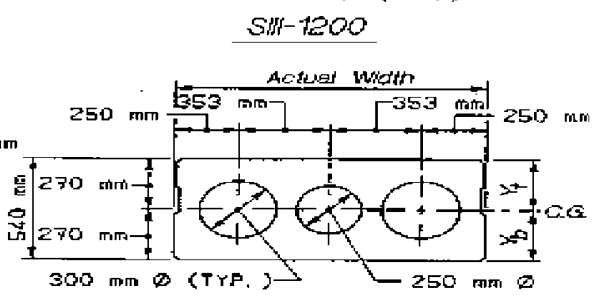

$5 n-1200$

\begin{tabular}{|c|c|c|c|c|c|c|c|c|c|c|c|}
\hline \multirow{2}{*}{$\begin{array}{l}\text { EEAMA } \\
\text { TYFE }\end{array}$} & \multicolumn{2}{|c|}{ MNTH } & \multirow{2}{*}{$\begin{array}{c}\text { DEPTH } \\
\text { (Tm) }\end{array}$} & \multirow{2}{*}{$\mathrm{mon}^{2}$} & \multirow{2}{*}{ 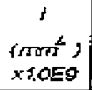 } & \multirow{2}{*}{ impe } & \multirow{2}{*}{$\underset{Y r}{Y}$} & \multirow{2}{*}{ 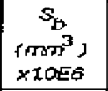 } & \multirow{2}{*}{$s_{+}^{s_{t}}\left(\operatorname{mon}^{3}\right)$} & \multirow{2}{*}{$\begin{array}{c}\text { MASS } \\
\text { (AOG/OS) }\end{array}$} & \multirow{2}{*}{$\begin{array}{l}\operatorname{man} x \\
\operatorname{spa}, \\
(\sin )\end{array}$} \\
\hline & $\begin{array}{l}\text { Nonn } \\
\text { (nton) }\end{array}$ & $\begin{array}{c}\text { Act. } \\
\text { (mons) }\end{array}$ & & & & & & & & & \\
\hline $3-200$ & 7.220 & 1206 & 300 & 356000 & ㄹ. 족 & $149.2 \angle 5$ & 150. 755 & 17. 903 & 17.724 & 85 & 9 \\
\hline $58-7200$ & 1220 & 1206 & 380 & 359230 & 5.197 & 18B. 691 & 191.309 & 27.562 & 27.165 & $\theta$ & 12 \\
\hline Sw- 200 & 1220 & 1206 & 460 & 398200 & 9.080 & 228.713 & 231.287 & 39.700 & 39.258 & 957 & 14 \\
\hline $5 n \times 200$ & 1220 & 1206 & 540 & 451280 & 14,640 & 269,111 & 271.889 & 54.604 & $53.0<6$ & 1085 & 97 \\
\hline
\end{tabular}

Figure I: PACES precast beam section

\section{OBJECTIVES OF A PARAMETRIC ENGINEERED COST FOR BRIDGES}

The objective of the bridge cost-benefit evaluation model was to develop an integrated quantitative and qualitative assessment technology for bridge infrastructure rehabilitation/ strengthening or renewal. The basic thesis was to provide:

(a) recommended alternative infrastructure repair/rehabilitation/strengthening solutions from accepted engineering practices;

(b) the adaptation of aircraft composite materials for dual use in infrastructure rehabilitation;

(c) accurate cost estimates for initial budget and feasibility decisions;

(d) the above three $(\mathrm{a}-\mathrm{c})$ decision tools prior to detailed design documents.

The resulting assessment technology can support engineering decision-making and provide new methods for value engineering analyses in the context of bridge deterioration. A goal of the cost-benefit model was to integrate the means and methods used by skilled environmental scientists and engineering practitioners - expert judgments, socio-political aspects, economics, engineering criteria, natural sciences, safety codes, historical data, descriptive factors, and specific project/site conditions into a unique assessment technology that can provide construction (material, labour, and equipment quantities) cost elements prior to detailed plans and specifications. An additional objective was to integrate the engineering and management decisions into a true lifecycle cost-benefit evaluation model, that includes deterioration predictions, life expectancy of alternative repairs, and the socio-political and economics of capital investment versus operations and maintenance costs.

The assessment technology uses a knowledge-based systems approach to combine engineering and materials technologies with economics, mathematics, natural sciences, and socio-political sciences to allow engineers to model alternatives to meet renewal 
goals. Furthermore, the assessment technology allows engineers to evaluate the costeffectiveness of dual-use technology retrofit solutions compared to rebuild options. A simple example is a decision to retrofit selected bridges by wrapping degraded columns with composite materials in context of a longer-term planned renewal and replacement national schedule - all combined to quantify the best lifecycle cost set of alternatives.

The ultimate goal of the bridge lifecycle cost-benefit model is to give engineers and policy makers the support system that will provide infrastructure planners a fundamental assessment technology to quantitatively evaluate current and future bridge systems in light of scientific, social, political (national versus local), fiscal, and environmental constraints. For engineers, the planned methodology provides an integrated process to contrast short-term solutions such as strengthening/retrofit/repair of existing bridges versus longer-term design and new construction alternatives. For policy makers, the assessment technology provides the needed feedback on cost managing our nation's bridge infrastructure. This assessment technology provides an innovative approach to engineering decision support systems and scientific aspects of emerging materials technologies.

\section{KNOWLEDGE-BASED SYSTEM AND INFERENCE ENGINE}

The lifecycle cost-benefit model is a knowledge-based assessment technology and decision support system that uses parametric engineering techniques with a finite field of both codified and unstructured data elements. The basic thesis of the design is that techniques are developed that model applications of emerging materials technologies through accepted engineering practices in order to develop better cost estimates for initial budget and feasibility decisions - without detailed design documents. The modelling concept uses knowledge-based systems to integrate expert judgments, engineering criteria, safety codes, historical data, descriptive factors, and specific project/site conditions. This unique process provides construction (material, labour, and equipment quantities) cost elements prior to detailed plans and specifications. Three main ideas that distinguish a knowledge-based system are the 'representation of knowledge, heuristic search, and the separation of knowledge from inference and control' (Harmon and King, 1985).

Knowledge is an integrated collection of facts and relationships which, when exercised, produces competent performance. Experiential knowledge or working memory is knowledge gained from hands-on experience. This typically consists of specific facts and rules-of-thumb (subsurface knowledge). This is in contrast to deep knowledge of formal principals or theories. Knowledge is differentiated from data in the organisation of facts and the ability to draw on organised data to make decisions. Both knowledge bases and traditional databases are designed to store information and differ significantly from each other in the types of information stored and types of interrelationships between data handled (Anvari, 1989). Knowledge-based decision support systems look to integrating the 'logic' of knowledge bases, capturing the concepts, and the technical computer programming techniques for solving engineering and mathematical problems.

Heuristic research refers to techniques usually acquired from experience versus theory. Heuristics are commonly called 'rules-of-thumb'. A pitfall of heuristics in civil engineering is that civil engineers, accustomed to working with proven equations and handbooks of factual data, tend to look more to deterministic solutions. Heuristic systems and rules-of-thumb are quite situational and can lead to errors and/or not give the same results every time they are run through a knowledge-based system. The lifecycle 
cost-benefit model overcomes this pitfall by using predefined, construction knowledge bases manipulated in a formal hierarchical work breakdown structure.

The lifecycle cost-benefit evaluation model utilises an inference engine and a hybrid of structured heuristics and conventional engineering algorithms which develops detailed material, labour, and equipment quantities in the context of rapidly changing legal and regulatory control data. The inference engine is that portion of a knowledge-based system that contains the inference and control strategies. The inference engine includes various knowledge acquisition, explanation, and user-interface sub-systems. Separation of the knowledge bases from the inference engine allows the expert to review the data/knowledge and pinpoint the exact rules or procedures that manipulate the knowledge.

\section{OVERVIEW OF PARAMETRIC ENGINEERED COST FOR BRIDGES}

The initial effort focused on the basic concepts, parameters, and attributes of the knowledge-based assessment technology. A summary of bridge designs utilising traditional construction materials such as wooden bridges, steel-girder bridges, reinforced concrete bridges, pre-stressed concrete bridges etc, and existing (though limited) data on fiber-reinforced polymeric (FRP) bridges were reviewed as well as as-built costs assessed. FHWA publishes highway statistics (FHWA, 1995), which assists in referencing structurally deficient bridges. Most emphasis was focused on defining engineering strengthening/repair alternatives and modelling the construction processes to apply materials technologies to simple span bridges. Thus, a review of appropriate repair/ strengthening procedure alternatives for the various bridge types was conducted. Asking bridge engineers the correct questions and defining parameters to model engineering alternatives and processes for application to bridge retrofit is an important component of the knowledge system. For example, a cofferdam around a pier may need to be constructed, in some scenarios but not all, before cleaning or application of composite wraps is done. The parameters relating to the processes, material, labour, and equipment projected to accomplish this task must be defined from the questions posed by the knowledge system. The information was gathered from various mediums including academic, industry, government lab reports, and DOT surveys. The data included construction processes, materials, equipment, labour, and cost. The output is a basic understanding of how materials technologies are adapted for bridge renewal in terms of engineering criteria. This bridge design information gathering and assessment of viable technical rehabilitation/strengthening options are the technical foundations of this lifecycle cost model. Specific engineering algorithms were used to augment the existing bridge models with composite wrapping, plating, or wet lay-up alternatives.

Heuristics, data, and expert knowledge were gathered through detailed library searches, surveys, field data collections, and expert interviews. Extensive work focused on classification of the information in relation to the parameters and attributes initially developed. Knowledge engineering processes with established experts were used to develop the architecture of the knowledge-based systems. This was critical to the success of the model in developing the overall framework of the inference engine for the knowledge-based assessment technology and decision support system. The 'know-how' fires the inference engine that integrates the materials technologies on the engineering requirements that translates through the knowledge-based heuristics to develop material, labour, and equipment line items from which project costs are calculated. Figure 2 is a pictorial representation of this complex interface and transdisciplinary interaction. The 


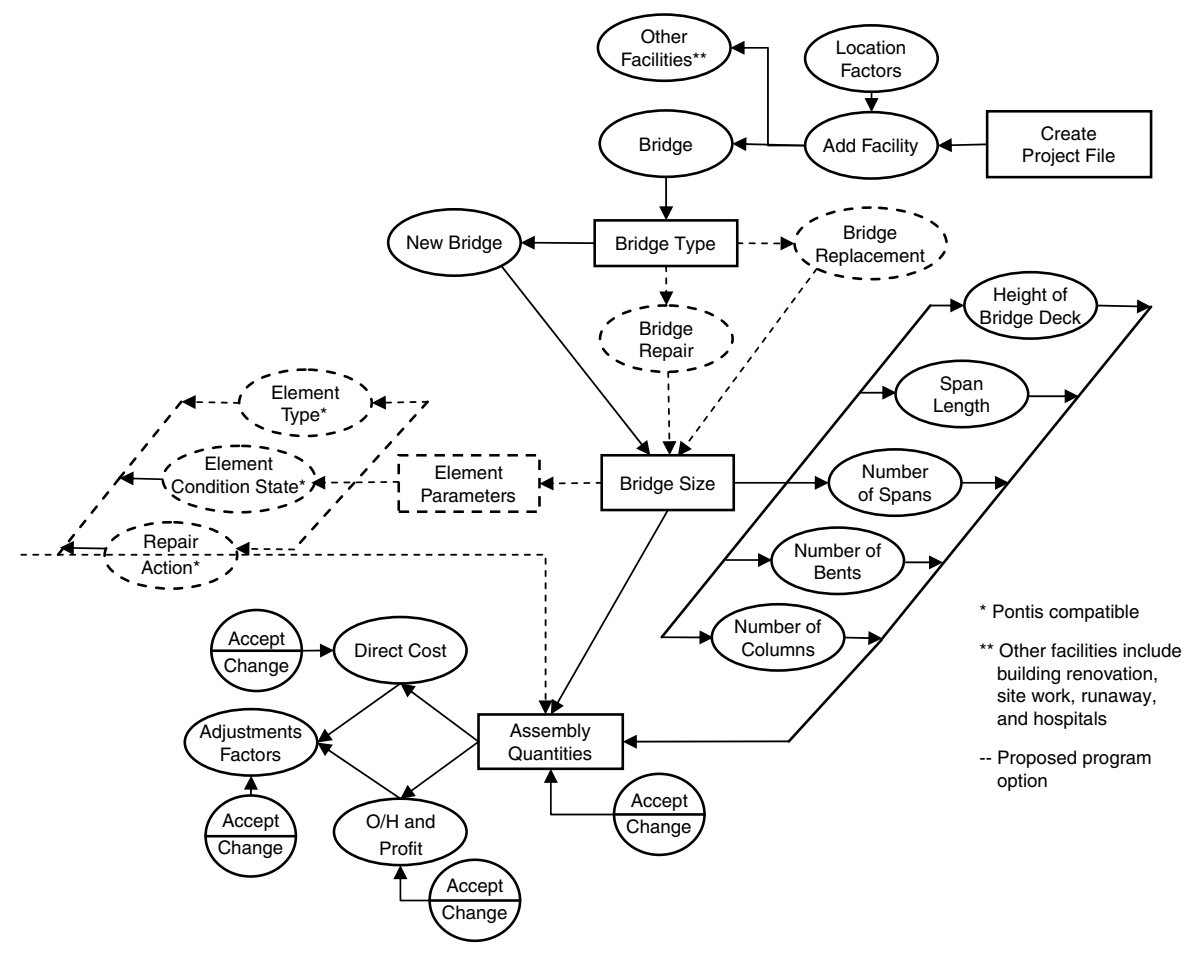

Figure 2: A sample inference engine

algorithms, data line items, robotic equipment alternatives, and integration of the bridge heuristics were incorporated into the modelling system.

Finally, a review and selection of the more complex bridge structures (such as continuous span; cable-stayed) and materials technologies algorithms was conducted. The assessment of repair and strengthening procedure alternatives as well as associated cost was evaluated. This also included methodology, materials, equipment, labour, cost, and integration of the bridge structures into the modelling system. Dissemination of the resulting modelling system should occur through the Department of Transportation agencies and Pontis users. Therefore, the system was designed to be compatible with Pontis. Forcing this compatibility with Pontis may sub-optimise the design from an engineer's perspective, but it will ease the implementation of the development into federal mandated bridge maintenance data.

The model provides a structured framework for future technological development. Federal and state agencies collaborate in bringing the assessment technology and decision support system to fruition and commercialisation. Subsequently, the modelling system is being expanded to provide additional applications, additional development, and validation to specific public agencies and engineering organisations. Also, expanded research to other material technologies and engineering applications could provide follow-on applications.

\section{PRACTICAL APPLICATION}

The modelling system initiates the expert system with input from condition assessments stored within National Bridge Inspection or Pontis Inventory and Appraisal reports. Knowledge systems were engineered to recommend a construction sequence, repair 


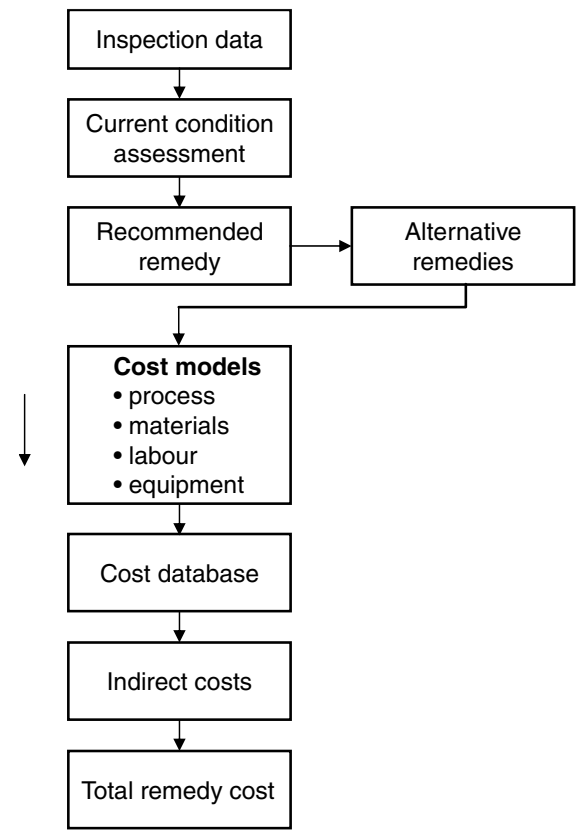

Figure 3: Modelling system flow chart

alternative, or remedy. Heuristics combined with accepted engineering practices and established repair/retrofit alternatives were used to translate the recommended action into specific material, labour, and equipment quantities. These quantities were then priced against current cost databases. The user has the option to evaluate alternative remedies and associated costs against the model recommended remedy. The model also provides the user the option to evaluate a unique designed remedy against previously established procedures. Figure 3 illustrates the modelling system.

The impact of the lifecycle cost-benefit model provides, for the first time, an assessment technology to evaluate the impact of rapidly changing regulatory requirements on infrastructure renewal and the construction industry. To the academic and scientific community, the lifecycle research pushes the bounds of knowledge-based systems. It provides seminal work in the most traditionally conservative industry (civil and environmental construction). And, possibly most important, it provides an education framework to teach complex, cross-discipline engineering, science, public policy, and legal theories in a practical integrated context. For individual construction project managers, the lifecycle benefit evaluation provides the assessment technology to conduct true value engineering on capital intense environmental compliance engineering solutions. It allows project managers to control the costs through the infrastructure renewal and rehabilitation. And, it provides project managers with a knowledge-based audit trail for negotiation with regulators or communicating lessons-learned throughout the industry. For the construction industry, the lifecycle cost-benefit evaluation provides a thorough and consistent assessment technology for handling the complex decisions and estimates in environmental compliance. A work breakdown structure and consistent approach to establishing engineering requirements from often conflicting environmental laws and regulations is invaluable. The lifecycle cost-benefit evaluation using this model will allow construction and policy makers to potentially save millions of taxpayers' and industrial capital dollars. 


\section{CONCLUSION}

The project-level lifecycle cost-benefit model for facilities and bridges includes the model design, knowledge-based systems, work breakdown structure, environmental compliance processes, engineering system algorithms, and procedures for exercising the knowledge-based assessment technology and decision support system for managing infrastructure deterioration and renewal. The lifecycle cost-benefit model began with basic research in idea development, seminal design, and limited prototyping. The lifecycle cost-benefit model development was initially scoped to simple administrative buildings and span bridge designs based on the desire to create a complete theoretical invention, prior to incorporating complex designs. The lifecycle cost-benefit model is currently being expanded to other more complex designs. For engineers, the planned methodology provides an integrated process to contrast short-term solutions such as strengthening/ retrofit/repair of existing facilities and infrastructure versus longer-term design and new construction alternatives. For policy makers, the assessment technology provides the needed feedback on cost managing our nation's facilities and infrastructure. The lifecycle cost-benefit evaluation using this model will allow construction and policy makers to potentially save millions of taxpayers' and industrial capital dollars.

\section{POSTSCRIPT}

This research, a unique collaboration by the authors at different academic institutions, was funded by NSF in multiple research grants. As the project progressed the collaboration included the US Department of Defense, Talisman Partners who provided PACES and additional funding (Talisman is now owned by EarthTec); CERF; AASHTO; several state DOT's; FHWA; and several other organisations and individuals. This project started with the authors discussing the cost of infrastructure, to obtaining NSF funds, and transitions from concept by the authors to development by AASHTO (from seed monies invested by several states). The most recent outcome of the project is the result of teaming among education, industry, government (state and federal), and professional organisations. The bridge project is available under AASHTO Trns* ${ }^{*}$ prt $^{\mathrm{y}}$ as Trns* port TRACER ${ }^{\mathrm{TM}}$ TRAnsportation Cost EstimatoR. This paper describes the seminal work of research that is becoming the cornerstone in innovative highway cost engineering.

\section{Acknowledgements}

The authors acknowledge the National Science Foundation for funding support for this research; Talisman Partners, Denver, Colorado and the USAF for use of the patented PACES methodology for research purposes; AASHTO for providing a copy of Pontis for research purposes, the University of Arizona; Wentworth Institute of Technology, and the Georgia Institute of Technology. The authors acknowledge Mrs Jacque Rast for designing the model screens. Student research assistants included Maria Patricia Garibaldi Thaesler and Mark N. Upton.

\section{References}

Air Force Civil Engineering Support Agency (AFCESA) (1995) Ordinance and Explosive Waste Remediation Model, Remedial Action Cost Engineering and Requirements (RACER) System. Model Manuals and Technical Reports, Tyndall AFB, FL.

Air Force Cost Center (AFCC) (1988) Expert System Shell Software Evaluation Final Report. Delta Research Corporation, Arlington, VA.

Air Force Legal Services Agency (AFLSA/JACPD) (1993) Patent Prosecution Office, Wright-Patterson AFB, OH. Arditi, D. (1991) 'An expert system for cost estimating software selection', Cost Engineer, 33, 6. 
Anvari, M.C.C.A. (1989) 'Knowledge engineered cost model (KECM) a methodology for costing during conceptual phase', Proceedings of the 23rd Annual DoD Cost Analysis Symposium, Leesburg, VA, USA.

Bell, L. (1999) Personal Telephone Communications on Bridge Cost Systems, Clemson University, South Carolina, USA.

Burns, T.J. (1993) 'Totally Integrated Construction Cost Estimating', Analysis and Reporting System U.S. Patent No. 5, 189, 606.

Federal Highway Administration (FHWA) (1995) The Status of the Nation's Highway Bridges: Highway Bridge Replacement and Rehabilitation Program and National Bridge Inventory, 12th Report to the United States Congress.

Federal Highway Administration (FHWA) (2002) 2002 Status of the Nation's Highways, Bridges, and Transit: Conditions \& Performance, Report to Congress.

Gallaher, F. and Gregory, R.A. (1993) Estimation and Analysis of Base Realignment and Closure Rounds I \& II, Air Force Civil Engineering Support Agency, Tyndall AFB, FL.

Gregory, R.A. (1992) Development of a Knowledge-Based System Approach for Decision Making in Construction Projects. PhD thesis, University of Florida, Gainesville, FL.

Harmon, P. and King, D. (1985) Expert Systems: Artificial Intelligence in Business, Wiley and Sons, Inc., New York.

Mendel, T.G. (1989) Case History - Parametric Estimating System, American Association of Cost Engineers, Transactions, Morgantown, WV.

Office Deputy Assistant Secretary of Defense (OASD) (1993) Parametric Facility Cost Estimating. A Report to the Congress. The Pentagon, Washington, DC.

Ohara, S. (1990) 'A New Forecasting methodology for Contingent Situations (Building Cost Estimations)'. Proceedings of the ISPA Conference, San Diego.

PACES (1997) Parametric Automated Cost Engineering System, Delta Technologies Group, Inc., Niceville, FL. Poulis, A. (1995) Director Information Services, Armstrong Laboratories, Environics Directorate, Tyndall AFB. Rounds, J.L. (1986) Expert Systems Potential As a Cost Engineering Tool, American Association of Cost Engineers, Transactions, Morgantown, WV.

U.S. Army Corps of Engineers (USA) (1988) Computer Aided Cost Estimating Systems (CACES), Control Estimate Generator (CEG), Users Manual CEHND-SP 88-219, Huntsville, AL.

Waid, F. (1978) Sara Systems, SARANET, Inc., Las Cruces, NM.

Yokoyama, A. (1988) The Integrated Cost Estimating Systems Technique for Building Cost, American Association of Cost Engineers, Transactions, Morgantown, WV. 